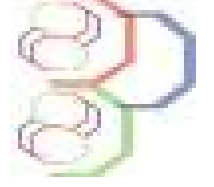

Journal of Applied Biosciences 64: 4763 - 4772

ISSN 1997-5902

\title{
The effects of forest destruction on the abundance, species richness and diversity of butterflies in the Bosomkese Forest Reserve, Brong Ahafo Region, Ghana.
}

Addai, G. and Baidoo P. K*.

Department of Theoretical and Applied Biology, Kwame Nkrumah University of Science and Technology, Kumasi, Ghana.

*Corresponding author's email address: pkbaidoo2002@yahoo.com

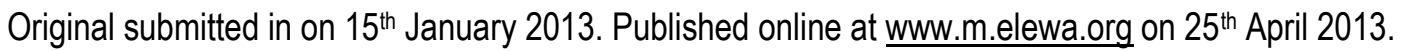

http://dx.doi.org/10.4314/iab.v64i1.88465

\begin{abstract}
Objectives: Despite the substantial loss of natural forest in the Bosomkese Forest Reserve, little is known on the effects of the massive habitat loss and degradation on forest biota. The study therefore assessed the effects of anthropogenic activities on butterfly species composition and abundance in the Bosomkese Forest reserve in the Brong Ahafo region of Ghana.

Methodology and Results: The effects of anthropogenic activities on butterflies were studied in three forest types identified in the forest reserve namely, disturbed canopy (DC) slightly disturbed canopy (SDC) and undisturbed canopy (UC), which was the control. The data on the butterflies were collected using fruit baiting traps on a 1 kilometer line transect selected in each of the study areas. Species richness and diversity were analyzed using Simpson's Diversity Index. Five butterfly families were identified during the study. These were: Numphalidae, Hesperiidae, Pieridae, Lycaenidae and Papilionidae. Nymphalidae recorded the largest number of species whilst Papilionidae was the least abundant. The undisturbed canopy recorded the largest number of butterflies whilst the disturbed canopy recorded the least number of butterflies. In terms of diversity, the undisturbed canopy showed the greatest diversity whilst the disturbed canopy showed the least diversity.

Conclusion and application of findings: Strict enforcement of forest laws by the law enforcement agencies and creating alternative source of livelihood for the people living in and around the forest reserve will help reduce the dependence on the forest as a source of livelihood.
\end{abstract}

\section{INTRODUCTION}

The exploitation of the natural forest by man for his survival has left in its wake massive degradation and destruction. Forests provide many social, economic, and environmental benefits to the survival of man. It is a source of timber and paper products, habitat for wildlife, recreational facilities as well as a sink for carbon dioxide thereby reducing global warming (Myers, et al., 2000). According to Swanes et al. (1997), close to $40 \%$ of pharmaceutical products used in the USA are either based on or synthesized from material compounds found in plants, animals, or 
microorganisms. Other uses of the forest include the promotion of eco-tourism, with financial benefits to the local citizens (The International Eco-Tourism Society, 1992), aesthetic and cultural benefits (Gormey, 1997), and scientific research. Forests have therefore contributed and continue to contribute to the survival of man.

In spite of the enormous benefits obtained from forests, large areas of the richest forests in the world have been cleared for fuel wood, timber products, and agriculture (Alonso et al., 2001). Based on a five- year study, FAO (2005) found that forest areas throughout the world were declining at a rate of about 7.3 million hectares per year, an area equivalent to Panama and Sierra Leone. The Upper Guinean forests of Ghana are among the most biologically unique in the world because they harbour a wide diversity of plant and animal species, many of which are found nowhere else, but these are also among the most critically threatened forests in the world (Larson et al., 2007)Only about $10-15 \%$ of original forest cover has not been destroyed and what remains is highly fragmented and degraded With the exception of sacred forest groves, virtually no forest cover remains outside the boundaries of designated reserves (Allotey, 2007).

A wide range of human activities such as farming and logging result in degradation of biotypes and loss of habitats. Loss of habitats such as unimproved grasslands and wetlands has been particularly dramatic and has led to reduction in Lepidoptera population in many European countries (Kudrna, 1986, Van Swaay and Warren, 1999., Balber and Erhardt, 2000., Ricketts et al., 2001). Population increase, coupled with urbanization and industrialization over the years have led to over-exploitation of forest resources resulting in high deforestation and disappearance of some plant and animal species (Fermon, 2002). Insects are important in environmental quality assessment because of their dominance in terrestrial ecosystem. Their short life cycles can result in rapid population responses to disturbances and their wide range of life style makes them sensitive to changes in biotic and abiotic environment. Butterflies are among the best-known insects that are involved in pollinating flowers. Butterflies are also good indicators of habitat quality as they respond rapidly to modification of vegetation (Robbins and Opler, 1996). They are extremely susceptible to unusual climatic conditions and certain species can be used to indicate certain environmental conditions. Butterflies are widely recognized as potentially valuable ecological indicator. Their presence can prove that habitats are suitable and indicate that certain conditions have been met. Butterflies are often colourful and sensitive to habitat and environmental changes. Therefore, any change in the forest can lead to changes in butterfly communities (Daily and Ehrlich 1995).

Certain butterfly species can be used to define environmental health simply by the presence of particular species. In contrasts, their absence may reflect declining health (Larson and Collins, 1998). The influence of landscape patterns on butterfly communities have been documented by different authors (Schneider et al., 2003., Natuhara et al., 1999). Sparks and Carey (1995) observed an influence of the floral composition on butterfly diversity. Similarly, Schoonhoven et al. (1998) reported that tree species diversity and cover had a positive effect on butterfly, but high proportion of large trees had a negative effect on butterflies.

Butterflies are day flying insects and relatively abundant in areas of luxuriant vegetation. They are sensitive to changes in temperature, humidity, and light levels that are caused by habitat changes. Changes in butterfly composition and abundance can point to suitable changes in forest habitat because the larvae have specialized host-plant requirements and adults are important for studies that can reveal the stabilization or decline of butterflies' species population due to habitat destruction or loss of forest ecosystem. The study therefore assessed the effects of anthropogenic activities on butterfly species composition and abundance in the Bosomkese Forest Reserve in the Brong Ahafo Region of Ghana. 


\section{MATERIALS AND METHODS}

Study Area: The study was undertaken in the Bosomkese Forest Reserve, which is located about $28 \mathrm{~km}$ East of Sunyani, Ghana and covers a total area of $138 \mathrm{~km}^{2}$. The Forest Reserve lies approximately between latitude $00 \mathrm{~N}, 7^{\circ} 15 \mathrm{~N}$, longitude $2^{\circ} 05 \mathrm{~W}$, and $2^{\circ} 30 \mathrm{~W}$. It is located within the semi-deciduous South East forest zone (Swanes, 1996) and has a mean annual precipitation of between $900 \mathrm{~mm}$ to $1500 \mathrm{~mm}$. There are two well-defined seasons, a rainy season from April to October and dry season from November to March. There are two rainfall peaks-May/June and September/October. However, long periods of drought are normal in December and January. The Forest Reserve is divided into 84 compartments with three designations based on the nature of their canopies. These include open canopy, where only selective logging is allowed under the strict forest laws and regulations, closed canopy where little or no human activities is allowed to take place, and disturbed canopy where the forest has been destroyed or near destruction due to the activities of the inhabitants of the area.

\section{Data collection on the butterflies}

Site selection: A one (1) kilometre long transect was selected from each of the three blocks. This selection was guided by the effort from the forest guards. Sampling of the butterflies for the study was carried out along the transects at 25 metres interval in each block which was randomly selected with the point of entry and accessibility in the area taken into consideration.

Butterfly sampling: A cylindrical trap of at least $90 \mathrm{~cm}$ in height was used to capture the butterflies. This height was used to minimize the escape of the butterflies once they enter the trap as recommended by (Barlow et al., 2007). Four different traps were set in each of the transect lines in all the blocks by hanging the trap nets on supports or shrubs and within $0.1 \mathrm{~m}$ and $1 \mathrm{~m}$ from the ground level (Bossat et al., 2006).

Traps were baited with different attractants such as pulverised, fermenting banana, flowers, and fermented fruit, covered in a rubber bucket two days prior to each collection. The prepared bait was mixed with fresh palm wine for maximum attraction of the butterflies and to speed up the fermentation process. The traps were hanged from ropes attached to branches of trees and or shrubs. Whenever a butterfly was captured, the bait was replaced with fresh one. The trap stations were labelled as treatment, $T_{1}, T_{2}, T_{3}$, and $T_{4}$. Baits were then put in plastic plates and placed in the trap to complete the procedure. Each trap was replicated four times. In addition to this, walk- and- catch -method using butterfly nets was employed within one kilometre line transect in each of the study area. With this, any butterfly observed and caught within the catchments area was counted. Data were collected monthly for six months (October 2010- March 2011) and for each month, sampling was replicated two times. Butterflies of West Africa (Larson, 2005) was the identification guide used for identifying the families and species. Data were collected on numbers of butterflies, relative abundance of butterflies with respect to habitat preference and dominance, species richness and diversity. Relative abundance and dominance of the butterflies with respect to habitat preference and dominance were calculated from the following formulae:

\section{- Relativeabundance $=\frac{\text { Number of individual butterflies }}{\text { Total number of butterflies captured }} \times 100 \%$}

- Relative dominance $=\frac{\text { Number of individual butterflies }}{\text { Total number of butterflies sampled in all the areas }} \times 100 \%$

- Species diversity of the butterflies was calculated using Simpson's Diversity Index. 
Simpson's Index (D) measures the probability that the individuals randomly selected from a sample will belong to the same species (or some category other than species).

$$
D=\sum \frac{n(n-1)}{N(N-1)}
$$

$\mathrm{n}=$ the total number of organisms of a particular species

$\mathrm{N}=$ the total number of organisms of all species (Goetz, 2007).

The value of $\mathbf{D}$ ranges between 0 and 1 . With this index, 0 represents infinite diversity and 1 , no diversity. That is, the larger the value of $D$, the lower the diversity.

Data analysis: Data collected were analysed using the Statistical Package for Social Science (SPSS) and the results were presented in means and percentages.

\section{RESULTS}

The number of butterfly counts in the forest types in Bosomkese Forest Reserve: A total of 119 individual butterflies belonging to 5 families were collected from October 2010 to March 2011. Thirty-one (31) were captured in the undisturbed forest canopy representing $26.05 \%$ of the total, 37 individuals in the slightly disturbed area (31.10\%) were collected whilst, the disturbed canopy recorded 51 individual butterflies accounting for $42.85 \%$ of the total number captured over the study period.

Numbers of Butterfly Families and Species: The Butterfly families identified were: Nymphalidae,
Data on butterflies were quantified in terms of abundance and species richness. Species diversity was calculated using Simpson's Diversity Index.

Papilionidae, Hesperidae, Pieridae and Lycaenidae. None of the forest types recorded all the five butterfly families Nymphalidae was the most dominant family in all the three forest types (Fig. 1). Apart from being present in all the canopy types, it also recorded the largest number of butterflies compared with the other families (Fig. 1). Hesperidae was the least abundant among the families identified and was absent from the disturbed canopy. Similarly, Papilionidae and Pieridae were totally absent from the slightly disturbed and undisturbed canopy respectively. 


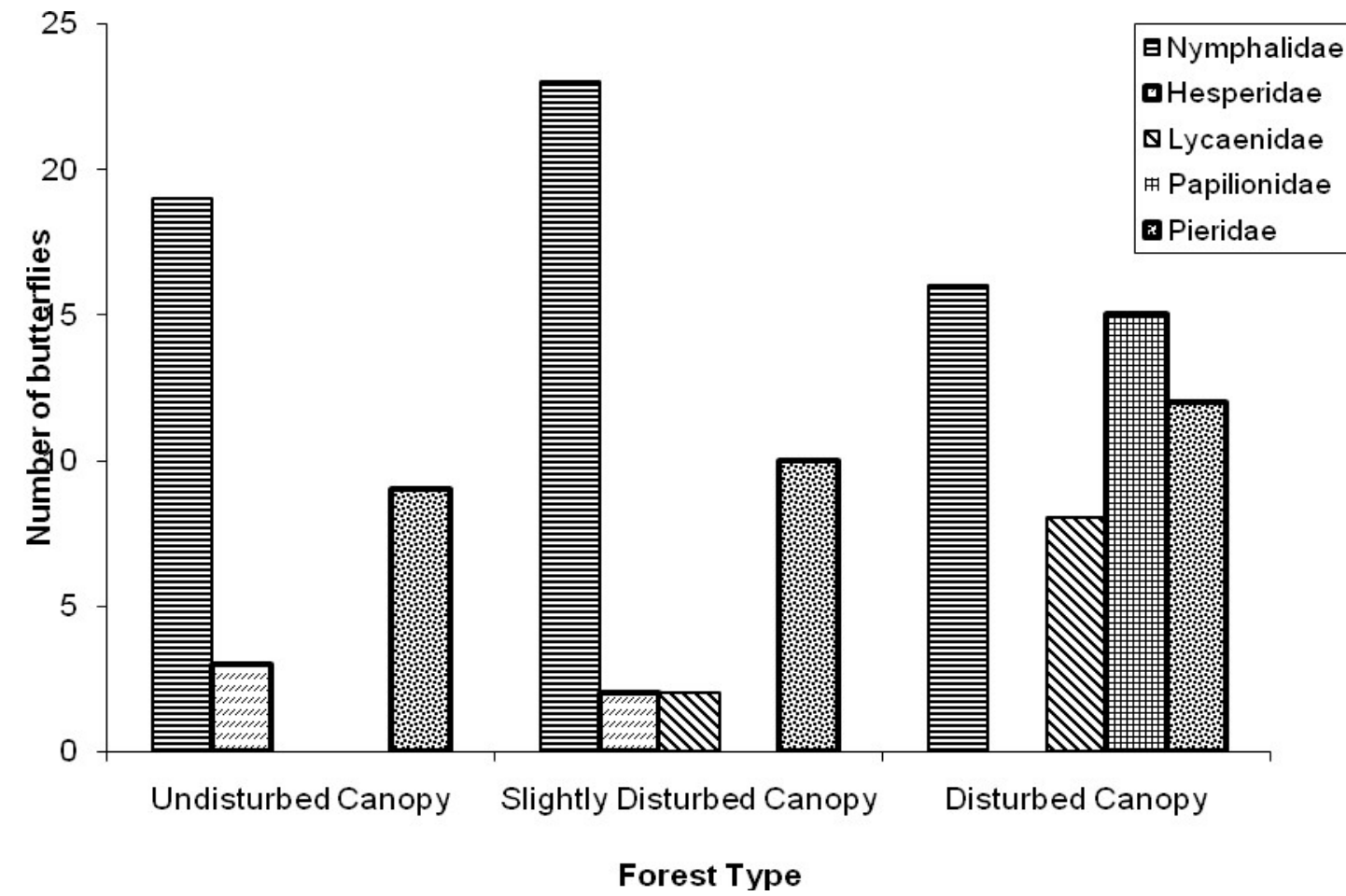

Fig. 1: Distribution and abundance of butterflies in the three forest types

In all a total of 19 butterfly species belonging to 5 families were identified. The Nymphalidae recorded the largest number of species (9), whilst Papilionadae, which was recorded only in the disturbed canopy, recorded only 1 species. Within the Nymphalidae,

Amaurina hecate (L.), Euphaedra zempa (L.) Charaxes cynthia (L.) and Neptis nysiades (L.) occurred in all three canopy types. Similarly, within the Pieridae, Catopsilia florella was identified in all three canopy types (Table 1).

Table 1: Distribution and relative abundance of butterflies in the three forest types

\begin{tabular}{lccc}
\hline Families and individual species of & \multicolumn{3}{c}{ Relative abundance (\%) } \\
\cline { 2 - 4 } Butterflies & UC & SDC & DC \\
\cline { 2 - 4 } Nymphalidae & $3.2(0.84)$ & $2.7(0.84)$ & $1.9(0.84)$ \\
Amaurina hecate hecate (L.) & $6.5(1.70)$ & 0.0 & 0.0 \\
Bicyclus italus (L.) & $12.9(3.40)$ & 0.0 & 0.0 \\
Bicyclus dorothea (L.) & 0.0 & $21.6(6.72)$ & 0.0 \\
Euryphura chalcis (L.) & & & \\
& $3.2(0.80)$ & $2.7(0.84)$ & $9.8(4.20)$ \\
Euphaedra zempa (L.) & $3.3(0.84)$ & $10.8(3.40)$ & $11.7(5.04)$ \\
Charaxes cynthia, cynthia (L.) & $22.5(5.88)$ & $18.9(5.88)$ & $7.8(3.40)$ \\
Neptis nysiades (L.) & $3.2(0.84)$ & $5.4(1.88)$ & 0.0 \\
Psuedacraea eurytus (L.) & $6.5(1.70)$ & 0.0 & 0.0 \\
Pentila hewitsonii (L.) & & & 0.0 \\
& & & 0.0 \\
Hesperiidae & $3.2(0.84)$ & 0.0 & 0.0 \\
Abantis tanobea (L.) & $3.2(0.84)$ & 0.0 & \\
Melphina malthina (L.) & $3.2(0.84)$ & $5.4(1.70)$ & \\
Eagaris decastigma (L.) & & & \\
\hline
\end{tabular}




\section{Pieridae}

Paseudopontia paradoxa (L.)

Catopsilia florella (L.)

Colotis euippe euippe (L.)

Mylothris atewa (L.)

Lycaenidae

Stempffera dorothea (L.)

Anthene wilsoni (L.)

\section{Papilionidae}

\begin{tabular}{lrrr} 
Papilio dardanus (L.) & 0.0 & 0.0 & $29.4(12.60)$ \\
\hline Total & 100 & 100 & 100 \\
\hline
\end{tabular}

NB. Figures in parenthesis represent dominance (\%) of each species in the Bosomkese Forest.

Larson, (2005), authored scientific names of butterflies.

Relative abundance of butterflies with respect to habitat preference : Results of the relative abundance of butterflies in the three canopy types are shown in Table 1. Among the individual butterfly species recorded in the undisturbed canopy, Neptis nysiades (L.) was the most abundant $(22.5 \%)$ while Abantis tanobia (L.), Melphinia malthina (L.), Eagaris decostigma (L.), Amaurina hecate hecate (L.), Eupheadra zampa (L.), Catopsilia florella (L.) and Pseudacraea eurytus (L.) were the least abundant $(3.2 \%)$. In the slightly disturbed canopy (SDC), Mylothris atewa (L.) was the most abundant (24.3\%). On the other hand, Amauris hecate hecate (L.), Euphaedra zampa (L.) and Catopsilia florella (L.) were the least abundant $(2.7 \%)$. Other species such as Bicyclus dorothea and $B$. italus were completely absent from this canopy type. Results from the disturbed canopy (DC), showed that Papilio dardanus (L.) was the most abundant (29.4) with Amaurina hecate hecate (L.) recording the least of abundance of $1.9 \%$. Papilio dardanus was recorded only in the disturbed canopy and completely absent from the other habitats.

Dominance of butterflies in the three forests types: Five (5) butterfly species namely Charaxes cynthia (L.), Amauris hecate hecate (L.), Neptis nysiades (L.) and Euphaedra zampa (L.) (Nymphalidae) and Catopsila florella (L.) (Pieridae) were found in all the three forest types. Neptis nysiades (L.) showed greater dominance in both the undisturbed canopy and slightly disturbed canopy $(5.88 \%)$ as against $3.40 \%$ in the disturbed area. However, Papilio dardanus, Anthene wilsoni and
Catopsilia florella were dominant in the DC canopy recording $12.60 \%, 6.72 \%$ and $5.88 \%$ respectively of the butterflies captured. Pentila hewotsonii (L.), Bicyclus italus (L.), Bicyclus dorothea (L.) (Nymphalidae), Psuedopontia parodoxa (L.)(Pieridae), Abantis tanobia (L.), Melphina malthina (L.) (Hesperiidae) were unique species recorded in the undisturbed canopy and these species showed evenness in abundance between 0.84 to 1.0(Table1). Two butterfly species Stempfferia dorothea (L.) (Lyceanidae) and Euryphura chacis (L.) (Nymphalidae) were unique in the slightly disturbed zone in the reserve. Papilio dardanus (L.) which was the most dominant among all the species $(12.6 \%)$ was found in the DC. Anthene wilsoni (L.) and Colotis euippe (L.) were found to be the unique species in the disturbed canopy. Three species namely Eagaris decastigma (L.), Mylothris atewa (L.) and Psuedacraea eurytus (L.) were common in both the undisturbed canopy and slightly disturbed canopy.

Species richness and diversity of butterflies in the Bosomkese Forest Reserve: The undisturbed canopy recorded the largest number of species and consequently had the highest species richness whilst the disturbed canopy recorded the least species richness (Table 2). In terms of diversity, the undisturbed canopy displayed greatest diversity of butterflies' species. The disturbed canopy had the least butterfly species diversity. The value of $D$ ranges between 0 and 1. With this index, 0 represents infinite diversity and 1 represents no diversity. That is, the larger the value of $D$, the lower the diversity. 
Table 2: Species richness and diversity of the butterflies in the Bosomkese forest Reserve betweenDecember 2010 and March 2011.

\begin{tabular}{lccc}
\hline Parameter & UC & SDC & DC \\
\hline Species richness & 14 & 10 & 8 \\
Diversity & 0.09 & 0.12 & 0.15 \\
\hline
\end{tabular}

\section{DISCUSSION}

The effect of forest destruction on the number of butterflies sampled in the three forest types in the Bosumkese Forest Reserve (BFR): The disturbed canopy recorded the largest number of butterflies, an indication that most of them preferred that habitat. This was the area where there was enough solar radiation up to the forest floor as result of the destruction of the canopy. Most butterfly species prefer open areas where the temperature is relatively high especially during the early part of the day (Larson, 2005). Similarly, Dumbrell and Hill (2005) indicated that butterflies prefer areas where the temperature ranges between $28{ }^{\circ} \mathrm{C}-33^{\circ} \mathrm{C}$ with optimum humidity. The least number of butterflies recorded in the undisturbed canopy was as a result of high moisture content and its associated low temperature (average $27^{\circ} \mathrm{C}$ ) which is only preferred by some of the species that are adapted to those conditions. According to Larson (1997), most of the butterfly species, during the early days of African history were recorded in the tropical rain forest areas but due to changing trends of the nature of the forest most of the species are near extinction or have gone into extinction particularly in the sub-Sahara African countries including Ghana. Human activities such as farming and logging were responsible for the fewer butterfly species in the disturbed canopy Basset et al. (1998) also indicated that with the destruction of the natural habitat, many of its animals go extinct and that 'we are losing approximately 100 species of organisms per day'. The slightly disturbed canopy recorded more butterflies than the undisturbed canopy but fewer than the disturbed canopy. This may be attributed to habitat preference by the butterflies.

Number of Butterfly Families Sampled: The number of species of butterflies belonging to Nymphalidae family was more than any of the other butterfly families identified during the study. Individual butterflies belonging to this family also accounted for $62.1 \%$ of all the butterflies sampled during the study. Butterfly species within the family were also sampled within all the canopy types. This might be due to the wide range of adaptations as well as wide habitat preference of
Nymphalidae within the Forest floor of West Africa. Most Nymphalidae are fruit feeding butterflies hence their large numbers in the Bosomkese Forest Reserve (Larson, 1994a). It is estimated that approximately 900 butterfly species occur in Ghana and most of these were identified to belong to the Nymphalidae (Larson (2005). This explains why larger numbers of them were captured in the Forest Reserve. Addae-Wireko (2008) also indicated that the Nymphalidae are the most widely known butterfly species in Ghana. This wide distribution of the Nymphalidae could also be attributed to their preference for many plant species. Butterflies of other families have been found to be strictly associated with particular plant species, making them plant species-specific (Larson (1997).

The distribution and relative abundance of butterflies in the three forest type in the Bosomkese Forest Reserve: Most of the butterfly species sampled in the closed canopy are classified as the forest type of butterflies that tolerate forest conditions. Bicyclus italus, B. dorothea, Pentila hewitsonii, Abantis tanobea and Melphina malthina were sampled only in the undisturbed canopy but completely absent from the other canopy types. This observation was in agreement with that by Larson and Collins (1998) that Pentila sp. Bicyclus sp. and Melphina sp. are found in greater numbers in forests of good quality in terms of the undisturbed nature of the canopy. Bicyclus dorothea also adapted well within the closed canopy as indicated by Larson (1994a) that most of these species are attracted to fermenting fruit and sap oozing from damaged trees, sometimes clogging up banana-baited butterfly trap, but they do not visit flowers. He also confirmed that they are adapted to forests of good canopy. Neptis nysiades was found to be the most abundant species in the undisturbed canopy and was well distributed in the other habitats. Larson (1995a) indicated that, this species is not particularly common in wet rainforest areas but is most frequently found in semi-deciduous forests preferring rather open areas or secondary growth in wetter forest regions. It was rather surprising 
that it was most abundant in the undisturbed canopy. Mylothris atewa was first discovered within the Atiwa Forest Range in the Eastern Region of Ghana. Most $M$. atewa are forest butterflies, but some penetrate into the Guinea Savannah along rivers and only handfuls are savannah-adapted (Larson 1994a). Occasionally, they may be found on flowers but are mainly fruit-feeding butterflies. This explains why they were more dominant in the undisturbed and slightly disturbed canopies. Euryphura chalcis was most abundant in the slightly disturbed canopy area of the reserve. Their dominance was no surprise as this butterfly species prefers dryforest conditions but quickly migrates to the deep forest area when the area is cleared (Larson 1995a). E. chalcis is strictly a forest type of butterfly. Papilio dardanus was most abundant in the disturbed canopy than any other species even though Anthene wilsoni, Colotis euippe euippe, Catopsila florella and Charaxes cynthia cynthia were equally abundant in the same area although to a lesser extent. All these butterflies especially Papilo sp, Anthene sp and Colotis sp are categorically labelled as savannah butterflies (Larson, 2001). Papilio $s p$ is common in degraded forests and open spaces where the land is most cultivated. It was therefore not surprising that this butterfly species was found only in the disturbed canopy. Larson (2006) stated that even though it is found in all types of forest, it does not penetrate the wetter forest types. It is mostly found in drier forests, but is now probably most common in the garden shrubs of major towns and in agriculture areas with trees and crops (Larson, 1994c).

The effect of forest destruction on the distribution and butterfly dominance in the three forest types in Bosumkese Forest Reserve: Five genera namely Charaxes, Amaurina, Neptis, Euphaedra and Catopsilia were found to tolerate a wide range of environmental conditions; hence they are described as ubiquitous species (Larson, 2005). They can survive in both open and closed forests whether dry or rain forest even though Catopsilia, Euphaedra and Charaxes were more dominant in the disturbed canopy. The forest habitat seems to provide conducive habitat for Pentila hewontsonii (L.), Bicyclus italus (L.), Abantis tanobia (L.), Psuedopontia paradoxa (L.) and Bicyclus dorothea (L.). These species thrive best in dense undergrowth where it may be difficult to capture them (Lewis, 2002) hence the smaller numbers trapped. However, Colotis euippe (L.), Anthene wilsoni (L.) and Papilo dardanus (L.) were very much adapted to the disturbed canopy hence their dominance over other species. They have been found to thrive well in the drier regions of the transitional zone, between the forest and savannah which explains their presence in Ghana (Larson, 1995b). According to Larson, (1994c) Papilio sp and Colotis sp for example cannot penetrate forests of good quality where the moisture content is high; hence they are purely savannah butterfly species. A. wilsoni thrives well in much drier forest of the Northern Ghana and was first observed around Upper West Region of Ghana (Larson, 1994c). Euryphura chalci was more abundant and unique than Stempffera dorothea in the slightly disturbed canopy. Euryphura chalci can tolerate and adapt well to the forest of secondary growth and more importantly open and drier forests than Stempfferia dorothea which can only adapt when the primary forest is cleared (Larson, 1995c). Most of the species that thrive well in the undisturbed canopy also have the tendency to survive in the slightly disturbed canopy. This may be due to the similarity in the conditions prevailing in the two areas within the forest reserve. On the contrary, due to wide differences in environmental conditions, $P$. dardanus, C.euipe and A.wilsoni were not observed in the undisturbed and slightly disturbed canopies. This was because most of the species observed in the disturbed canopy can also be observed on even a brief walk through agricultural lands and village forest zones, though the speciescomposition differs from locality to locality. Very few would ever be encountered within forests of good quality (Larson, 1994c).

The effect of forest destruction on species richness and diversity in the three forest types in the Bosumkese Forest Reserve: The undisturbed canopy recorded high species richness and consequently high diversity in the butterfly species. This was due to the heterogeneous nature of the vegetation in the undisturbed canopy which attracted butterflies of different species. Over the years the decrease of closed forest has led to the development of secondary habitats, ranging from laterite to almost rock-like soil with hardly any vegetation to derived savannah, various combinations of mixed agriculture, and finally tree crops such as cocoa and kola nuts. In such areas butterfly diversity has decreased considerably and true ubiquitous species have thrived, while some savannah species of butterflies have invaded these degraded forests. However, a small number of species have greatly benefited and are now much more common in West Africa than they ever were (Larson 2005). This explains why species richness as well as diversity was 
much lower in the disturbed canopy than the undisturbed canopy. The species diversity was

\section{CONCLUSION}

The undisturbed canopy recorded the largest number of species and therefore the highest species richness and species diversity compared to the other two forest types. This was an indication that human activities have negatively affected the butterfly species. Five butterfly families belonging to 19 species were identified in the forest reserve. Papilio dardanus (Papilionidae) was the

\section{REFERENCES}

Addae -Wireko, L. (2008). Mapping distribution of butterflies in central Bobiri Forest Reserve and investigation of logging and stage of regeneration on butterfly species richness and diversity. MSc. thesis. KNUST.Pp.11-28.

Allotey, J. A. (2007). Poverty and the environment. Daily Graphic. July, $22^{\text {nd }} 2006$, pp. 7.

Alonso, A. F., Dallmier, E., Grane, K. and Raven, P. (2001). Biodiversity: Connecting with Tapestry of Life. Smithsonian Institutional Monitoring and Assessment of Biodiversity Program and President's Committee of Advisors on Science and Technology, pp 371-389.

Balber, O. and Erhardt, A. (2000). Consequences of succession on extensively grazed grasslands for Central European butterfly communities: Rethinking conservation practices. Conservation Biology 14: 746-757.

Barlow, J. S. Overal, W.L., Araujo, I.S., Gardner, T.A. and Peres, C.A. (2007). The value of primary, secondary and plantation forest for fruitfeeding butterflies in the Brazilian Amazon. Journal of Applied Ecology,44(5):1001-1012.

Basset, Y., Novtny, V., Miller, S. E. and Springate, N. D. (1998). Assessing the impact of forest disturbances on tropical invertebrates: Some Comments. Journal of Applied Ecology, 35(3):461-466

Bossat, J. L., Opuni-Frimpong, E., Kuuda, S. and Nkrumah, E. (2006).Richness, abundance and complementarities of fruit-feeding butterfly species in Relict Sacred Forests and Forest Reserves in Ghana. Biodiversity and Conservation. 15: 333-359.

Daily, G. C. and Ehrlich, P. R. (1995). Preservation of biodiversity in small rainforest patches: rapid therefore directly related to species richness of a locality (Hamer et al., 1997).

only species recorded in the destroyed canopy, an indication that this species is adapted to open areas of the forest. Forest resources serve as sources of livelihood for man and other animals. It is therefore necessary for the forest to be used in a sustainable manner for the use of future generations.

evaluation using butterfly trapping. Biodiversity and Conservation, 4:35-55.

Dumbrell, A. J., and Hill, J. K. (2005). Impacts of selective logging on canopy and ground assemblages of tropical forest butterflies: Implications for sampling. Biological Conservation, 25 (1):123-131.

FAO (2005). Global Biodiversity Assessment, 2002 FAO, Rome, 127pp.

Fermon, H. (2002). The butterfly community of a managed West African rainforest: patterns of habitat specificity, diversity, stratification and movement. George-August-University Gottingen, 637-643pp.

Goetz, S., Steinberg, D., Dumbuyah, R. and Blair, B. (2007). Laser remote sensing of canopy habitat heterogeneity as a predator of bird species richness in an eastern temperature forest, USA Remote Sensing of Environment, 108(3): 254-263.

Gormey, B. (1997). The forest and our destiny. Green Dove. No. 15, pp 8-9.

Hamer, K. C., Hill, J. K., Lace, L. A, and Langan, A. M. (1997). Ecological and bio- geographical effects of forest disturbances on tropical butterflies of Sumba, Indonesia. Journal of Biogeography 24:67-75.

Kudrna, O. (1986). Butterflies of Europe. AULA- Verlag, Darmstadt, Germany, $323 \mathrm{pp}$.

Larson, T. B. (1994a). Fruiting-Feeding butterflies in large numbers on flowers. Entomologists' Record and Journal of Variation 106: 157-158.

Larson, T. B. (1994c). The butterflies of Ghana their implication for conservation and sustainable use. Report to IUCN and Dept of Game and Wildlife, Ghana. 
Larson, T. B. (1995a). Butterflies in Kakum National Park, Ghana Metamorphosis 6; 138-145

Larson, T. B. (1995b). Butterflies in Kakum National Park, Ghana Metamorphosis 6; 138-145

Larson, T. B. (1995c). Butterflies biodiversity and conservation in the Afro-tropical region. In: Pollin A.S. (Ed). Ecology and conservation of butterflies, pp. 290-303. Chapman and Hall.

Larson, T. B. ((1997). Butterflies of West African origin, natural history, diversity and conservation. Draft Systematic point. Larson-CD Rom, Monila, 395-399.

Larson T. B., and Collins, S. C. (1998). Two new species of Anthene (Lepidoptera, Lycaenidae ) from West Africa, Lambillinionae, 98; 372376.

Larson T. B. (2001). The butterflies of Ankasa/Nini Suhyien and Bia. Protected area systems in Western Ghana. Protected area development project, UGL/Ghana Wildlife department.

Larson T. B. (2006). The butterfly fauna and its contribution to the objectives of the Protected area Systems. WDSP Report Number 63 Wildlife Division (Forestry Commission) and IUCN (World Conservation Unit), 202-218.

Larson, T. B., Adusei-Poku, K., Boersman, H., Safian, S., and Baker, J. (2007). Bobiri Sanctuary in Ghana-Discovering its Butterflies (with a checklist of the 930 butterflies of Ghana) Metarmorphosis, 18(3), pp. 87-126.

Larson T. B. (2005). Butterflies of West Africa. Vol 2, 596 pp, 125 plates. Apollo books.

Lewis, O. T. (2002). Effects of experimental selective logging on tropical butterflies. Conservation Biology 15: 389-400.

Myers, N., Mittermeier, R. A., Mittermeier, C. G., d. Fonseca, G. A. B. and Kent, J. (2000). Biodiversity hotspots for conservation priorities. Nature 403: pp 853-858.

Natuhara, Y., Imai, C. and Takahashi, M. (1999). Pattern of land mosaic affecting butterfly assemblage at Mt. Ikoma, Osaka. Ecological Research. 14: 105-118.

Ricketts, T. H., Daily, G. C. Ehrlich, P. R. and Fay, J. P. (2001). Countryside biogeography of moths in a fragmented landscape: Biodiversity in native and agricultural habitats. Conservation Biology. 15(2) 378-388.

Robbins, R. K. and Oppler, P. A. (1996). Butterfly Diversity and a Preliminary Comparison with Bird and Mammal Diversity. Pp 69-84. In: M. L. Reaka-Kudla, D. E. Wilson, E. O. Wilson, (eds.) Biodiversity II Washington DC. Joseph Henry Press.

Schoonhoven, L. M., Jermy, T. and VanLoon, J. J. A. (1998). Insects and flowers: the beauty of mutualism. In: Schoonhoven, L. M., Jermy, T. and VanLoon, J. J. A. (Eds) Insect Plant Biology, 315-342. Chapman and Hall.

Schneider, C. Dover, J. and Fry, L. A. (2003). Movement of two grassland butterflies in the same habitat network: The role of adult resources and size of the study area. Ecological Entomology. 28: pp 219-227.

Sparks, H. T. and Carey, P. D. (1995). The responses of species to climate over two centuries: An analysis of the Marsham Phenological Record. Journal of Ecology 83: 321-329.

Swanes, M. D. Agyemang, V. K., Kyere, B., Orgle, T. K., Thompson, J. and Veenendal, E. M (1997). Ecology of Forest trees in Ghana. ODA Forestry No. 7 London, 76pp.

Swanes, M. D. (1996). Rainfall and Soil fertility as factors limiting forest species distribution in Ghana J. Ecol. 84:419-428.

The International Ecotourism Society (1992) Supporting and uniting conservation, communities and sustainable travel. (www.ecotourism.org) pp 14.

Van Swaay, C. and Warren, M. (1999). Red data book of European butterflies (Rhopalocera). Nature and Environment: No. 99. Council of Europe Publishing, pp 332-342. 